\title{
Configurações
}

Revista de sociologia

19 | 2017

Vária

\section{Metamorfoses na política, valores empresariais e governação em saúde em Portugal}

Metamorphoses in politics, entrepreneurial values and health governance in Portugal

Métamorphoses dans la politique, les valeurs d'entreprise et la gouvernance de la santé au Portugal

\section{Ana Paula Marques e Ialê Falleiros}

\section{(2) OpenEdition}

\section{Journals}

Edição electrónica

URL: http://journals.openedition.org/configuracoes/4009

DOI: $10.4000 /$ configuracoes.4009

ISSN: 2182-7419

\section{Editora}

Centro de Investigação em Ciências Sociais

Edição impressa

Paginação: $72-88$

ISSN: 1646-5075

\section{Refêrencia eletrónica}

Ana Paula Marques e lalê Falleiros, « Metamorfoses na política, valores empresariais e governação em saúde em Portugal », Configurações [Online], 19 | 2017, posto online no dia 30 junho 2017, consultado o 04 maio 2019. URL : http://journals.openedition.org/configuracoes/4009 ; DOI 10.4000/configuracoes.4009 
Marques, Ana Paula; Falleiros lalê - Metamorfoses na política, valores empresariais e governação em saúde em Portugal. Configurações, vol. 19, 2017, pp. 72-88

\title{
Metamorfoses na política, valores empresariais e governação em saúde em Portugal
}

\author{
ANA PAULA MAROUES* \\ Professora Associada, com Agregação, da Universidade do Minho \\ IALÊ FALLEIROS** \\ Professora e pesquisadora do Laboratório do Trabalho e da Educação Profissional da \\ Escola Politécnica de Saúde Joaquim Venâncio (EPSJV/Fiocruz)
}

\begin{abstract}
Resumo
O artigo avalia o impacto das atuais estratégias empresariais na governação em saúde a partir de dois principais relatórios de enquadramento das políticas públicas, nomeadamente O Futuro da Saúde em Portugal (APAH/ APDH, 2007) e Um Futuro para a Saúde: Todos temos um papel a desempenhar (Crisp, 2014), confrontando-os com visões institucionais obtidas através de entrevistas aprofundadas a informantes privilegiados. Com base no projeto de mundialização da saúde ancorada na perspetiva neoliberal de Terceira Via, pretende-se analisar as mudanças programadas nas relações sociais de trabalho e do cuidado à saúde da população portuguesa. Os resultados evidenciam que as reformas projetadas para o futuro da saúde em Portugal já estão em curso há pelo menos uma década, conformando um processo de privatização e empresarialização do setor da saúde.
\end{abstract}

Palavras-chave: Portugal, políticas de saúde; neoliberalismo, privatização, profissionais de saúde.

\footnotetext{
Abstract

"Investigadora do Centro Interdisciplinar de Ciências Sociais (CICS.NOVA/ CICS-UMinho). E-mail: amarques@ics.uminho.pt

** Pesquisadora do Grupo de Estudos e Documentação sobre o Empresariamento da Saúde (GPDES IESC/UFRJ).E-mail: ialefalleiros@gmail.com
} 
Metamorphoses in politics, entrepreneurial values and health governance in Portugal The article evaluates the impact of current business strategies on health governance from two main policy reports, namely The Future of Health in Portugal (APAH/ APDH, 2007) and A Future for Health - We all have a role to play (Crisp, 2014), confronting them with institutional visions gathered through in-depth interviews with privileged informants. Based on the globalisation of health's strategy anchored in the neoliberal perspective of the Third Way, it is intended to analyse the scheduled changes in social relations of work and health care of the Portuguese population. Our main findings show that the reforms planned for the future of health in Portugal have been underway for at least a decade, forming a process of privatisation and entrepreneurship in the health sector.

Keywords: Portugal, health policies, neoliberalism, privatisation, health professionals.

\begin{abstract}
Résumé
Métamorphoses dans la politique, les valeurs d'entreprise et la gouvernance de la santé au Portugal

Cet article évalue l'impact des stratégies d'entreprise actuelles en matière de gouvernance de la santé à partir de deux des principaux rapports d'encadrement des politiques publiques, notamment L'avenir de la santé au Portugal (APAH/APDH, 2007) et Un avenir pour la santé - nous avons tous un rôle à jouer (Crisp, 2014), les confrontant à des idées institutionnelles acquises grâce à des entretiens approfondis avec des informateurs clés. Sur la base de la stratégie de mondialisation de la santé, ancrée dans une perspective néo-libérale de la troisième voie, notre but est d'analyser les changements prévus dans les rapports sociaux du travail et des soins de santé de la population portugaise. Les résultats montrent que les réformes prévues pour l'avenir des soins de santé au Portugal sont déjà en cours depuis au moins une décennie, en conformant un processus de privatisation et de corporatisation du secteur de la santé.
\end{abstract}

Mots-clés : Portugal, politiques de santé, néo-libéralisme, privatisation, professionnels de la santé.

\title{
Introdução
}

A literatura académica recente indica que, em Portugal, o Serviço Nacional de Saúde (SNS), criado em 1979, sofreu mudanças ao longo das diferentes conjunturas político-económicas, mantendo-se, no fim da primeira década do século XXI, como "um sistema público, financiado por impostos, que funciona como seguro público, universal e obrigatório", ainda que o Estado permaneça como "prestador de serviços de saúde e proprietário de uma parcela significativa do sistema" (Silva, 2012: 123).

Esse cenário é corroborado por outro estudo que aprofunda a compreensão sobre as metamorfoses na sociedade portuguesa e suas relações com a saúde (Correia, 2012). Neste estudo, afirma-se que as estratégias de difusão 
da cultura empresarial na área da saúde incidiram fortemente sobre as novas técnicas de administração, imprimindo nova racionalidade à gestão dos serviços públicos de saúde, mormente sobre os gastos com o consumo e os recursos humanos, por via da individualização das relações laborais. A capacidade de este setor ser "eficiente e apto a jogar com as regras do mercado" intensifica-se no quadro da política mais recente do Estado Português, que coincide com a intervenção financeira da Troika ${ }^{1}$, a partir de 2011. Fica "em aberto e na completa indefinição como os cuidados se prestam, por quem e sob que condições”, ao mesmo tempo que se promove "um contexto de concorrência entre o setor público e o setor privado" (Correia, 2012: 87).

A privatização dos serviços de saúde faz parte de um processo mais vasto de ressimbolização do espaço social de trabalho (Marques, 2009). Este apresenta-se indissociável das transformações dos modelos empresariais e de governação que corporizam a "cultura do novo capitalismo" (Sennett, 2007) na mesma linha dos argumentos que sustentam o "novo espírito do capitalismo" (Boltanski e Chiapello, 1999). São vários os argumentos nesse sentido, designadamente, o domínio da lógica do "curto prazo" no retorno do investimento financeiro por parte das empresas constituídas por acionistas (Sennett, 2007); a progressiva destruição de trabalho vivo (postos de trabalho e/ou profissões diversas) pela parametrização e imaterialização do mesmo em sistemas integrados de informação e gestão (Castells, 2003); e a crise da eficácia e eficiência dos modelos de governação de índole burocrático-racionalizadora, potenciando o “emagrecimento" das estruturas organizacionais com externalização de parte da produção de bens/serviços (Boyer, 1986).

Ora, as transformações nos contextos e práticas do exercício profissional da maior parte dos grupos profissionais (desde médicos a enfermeiros, incluindo profissionais associados à área da saúde) parecem estar relacionadas com a generalização de princípios de mercado e de um discurso gestionário e controlador explícito na lógica de resultados, qualidade e avaliação (Marques, 2014; Bezes e Dumazière, 2011; Macedo, 2002). Igualmente, as recomposições dos mercados (trans)nacionais, que caracterizam estes profissionais da área da saúde, podem ser compreendidas como resultantes de estratégias de fechamento social/ desprofissionalização e dos paradoxos emergentes das "novas direções” do profissionalismo (Evetts, 2012, 2010; Kulmann, 2012).

Neste artigo, pretende-se contribuir para o aprofundamento do conhecimento sobre a agenda política empresarial para o setor da saúde. A reflexão é apresentada em três secções, além da introdução e das notas finais. Na primeira secção, situamos teoricamente o conceito de mundialização da saúde ancorado

1 A 6 de abril de 2011, Portugal fez um pedido de assistência financeira à Comissão Europeia para garantir condições de financiamento ao país e ao seu sistema financeiro. Resultou daqui um memorando de entendimento entre o Banco Central Europeu (BCE), a Comissão Europeia e o Fundo Monetário Internacional (FMI). 
nos pilares do projeto designado como neoliberal de Terceira Via. Na segunda secção, apresenta-se uma discussão sobre as transformações nos referenciais das profissões na atualidade. Na terceira secção, apresenta-se a agenda empresarial para a saúde em Portugal a partir da análise de documentos selecionados e entrevistas em profundidade produzidas para este estudo.

\section{0 neoliberalismo de Terceira Via e a mundialização da saúde}

Desde o Consenso de Washington (1989) que o neoliberalismo vem sofrendo modificações. A partir do tratamento a ele conferido pelo programa da Terceira Via, o neoliberalismo passou a incidir sobre as relações sociais de trabalho, para além da lista de recomendações económicas voltadas para o aumento de produtividade, lucratividade das empresas e negócios privados. A atualização promovida pela autoproclamada social-democracia reformada logrou a coesão social necessária em favor do projeto capitalista para o século XXI, com recurso à desregulamentação laboral e ao enfraquecimento dos direitos profissionais conquistados/ concedidos pelo Estado de Bem-Estar (Neves, 2010).

$\mathrm{Na}$ arena de disputa de projetos societários, na segunda metade da década de noventa do século XX, o capitalismo “de face humana” deu vantagem aos projetos antagónicos, por meio de um programa definido a partir de quatro pilares: 1) o despontar de uma ordem social pós-tradicional com o fim da polarização ideológica e geopolítica característica da Guerra Fria e o desenvolvimento de uma globalização intensificadora; 2) o fortalecimento de um novo Estado democrático; 3) o florescimento de uma sociedade civil ativa; 4) e o ressurgimento do individualismo como valor moral radical (Giddens, 2001). Em linhas gerais, de acordo com esta perspetiva, estaríamos a viver um novo momento histórico em que as tradições são postas em cheque por uma cultura cosmopolita que, por sua vez, forja um novo individualismo e um estilo de vida cujas escolhas políticas passam a ser motivadas não por visões do mundo constituídas a partir de experiências de classe social, mas por critérios de eficiência, pragmatismo e inovação. Esta autonomia individual seria constituinte do aumento da reflexividade social, orientadora de escolhas baseadas na informação e no conhecimento disponíveis, em detrimento de ideologias. Graças à reflexividade social, as solidariedades desgastadas pela velha ordem seriam recuperadas, fundando uma cidadania ativa, na qual os indivíduos assumiriam novas responsabilidades a partir dos seus interesses e valores pessoais. O novo Estado democrático, nesse projeto, teria como premissa a abertura dos canais de participação de cidadãos ativos nas decisões políticas e nas ações antes restritas ao próprio Estado (Neves, 2010).

A Terceira Via supõe, tal como a doutrina (neo)liberal, que a superação da crise geral está na reforma do Estado e na sua desresponsabilização pela execução direta das políticas sociais. Entretanto, não defende somente a privatização 
e a passagem dessa responsabilidade para o mercado, mas, sobretudo, a sua transferência para as organizações da sociedade civil, por meio da criação do conceito de "público não-estatal" ou "terceiro setor" (Falleiros, Pronko e Oliveira, 2010).

O ideário neoliberal de Terceira Via tem-se difundindo nas diferentes áreas do conhecimento por meio de autores de feições teóricas diversas, que atuam na formulação de documentos produzidos por organismos financeiros internacionais, tais como, por exemplo, o Relatório sobre o Desenvolvimento Mundial de 1997, intitulado O Estado num Mundo em Transformação (Banco Mundial, 1997). O amplo programa de reformas políticas daí resultante visa reordenar a estrutura e o funcionamento dos sistemas de saúde, designado "mundialização da saúde". Esta corresponde ao avanço das forças de mercado sobre as atividades e os serviços públicos, à proliferação de valores e ideais empresariais sobre as atividades/serviços, ao exercício profissional orientado para a eficiência e ao comportamento dos clientes ou população-alvo. A base material fornecida pelas novas tecnologias de informação e comunicação, somadas à automação e à robótica, conflui para o desenvolvimento de uma cultura organizacional nos serviços de saúde baseada no modelo empresarial de gestão e de controlo do trabalho. Em Portugal, este movimento de "mundialização da saúde" assume relevância a partir dos primeiros anos do século XXI pela difusão da racionalidade empresarial sobre as atividades e os serviços públicos, sofrendo um avanço significativo a partir de 2011 por meio da ampliação da privatização desses serviços. Neste contexto, o ideário neoliberal de Terceira Via também tem expressão no pensamento político da saúde e é coincidente com as reformas no SNS, as mudanças nas relações laborais e nos contextos profissionais de saúde.

\section{Gestão, individualização e "erosão" da autonomia dos profissionais de saúde}

Assumir a confiança, a discricionariedade e a competência historicamente reivindicadas para se ser um profissional implica reposicionar o debate sobre as "margens de autonomia" que o mesmo possui nos diversos contextos organizacionais ${ }^{2}$. Ser "profissional" significava deter autoridade da ciência, apoio do Estado e confiança pública. Atualmente, importa analisar as reconfigurações dos grupos profissionais em relação aos diversos aspetos da sociedade contemporânea e aos debates teóricos de fundo sobre a mundialização da saúde.

2 Neste domínio específico, são relevantes as transformações ao nível da formação académica superior que se confronta com uma multiplicidade de titulações em áreas afins. Estas conduzem quer a uma oferta diversificada de profissões certificadas ligadas aos serviços de saúde, quer à maior pressão de "monopolização" do mercado de trabalho perante o excesso de oferta de títulos em determinadas áreas (por exemplo, farmácia, nutrição, radiologia, fisioterapia, análises clínicas). 
São várias as controvérsias e tensões que indiciam discussões relevantes na relação entre Estado, trabalho e profissões. Estas tendem a situar-se numa linha de pensamento orientada ou para uma perspetiva anglo-saxónica ou francófona (Svensson e Evetts, 2010; Dubar e Tripier, 1998) ${ }^{3}$. Recentemente, são, ainda, convocados contributos que visam integrar neste debate as transformações decorrentes dos modelos organizacionais e de gestão pela adoção de pressupostos de mercado e de cariz privado nas políticas de reconfiguração do setor público na saúde. Em concreto, estas transformações caracterizam-se, em grande medida, pelo SNS implicar a passagem de uma parte significativa dos hospitais públicos, primeiro transformados em Sociedades Anónimas (SA) e, logo depois, em Entidades Públicas Empresariais $(\mathrm{EPE})^{4}$, dando corpo à tendência de empresarialização da rede de cuidados de saúde hospitalares (incluindo a privatização, a pressão para a qualidade e a externalização de serviços) ${ }^{5}$. Mais recentemente, no ideário político-gestionário neoliberal, encontram-se também serviços e estabelecimentos de prestação de saúde (agrupamentos de centros de saúde e unidades locais de saúde) que integram as redes de cuidados de saúde primários e continuados.

É nesta conjuntura que se compreende mudanças no setor da saúde português como "a separação entre financiamento e prestação dos cuidados”, “a criação de um mercado interno regulado pelo Estado, garantindo competição entre prestadores públicos e entre prestadores públicos e privados", as "alterações do sistema remuneratório dos médicos, afastando-os do regime de funcionário público (salários) e aproximando-o de profissionais liberais (honorários, diversificação salários)" e "a valorização dos cuidados de saúde privados ou concessionados" como resposta às listas de espera (Silva, 2012: 123). Associadas às reestruturações organizacionais e aos modelos de governação, as restrições orçamentais, acompanhadas quer de políticas de subfinanciamento de serviços diversos até então sob tutela do Estado, quer de cortes nas transferências dos orçamentos públicos para o SNS, explicam a menor capacidade de endogeneização destes profissionais no mercado interno de trabalho. O desemprego afigura-se como inevitável para muitos deles, bem como a tendência para a precarização das condições salariais e contratuais. Nestas circunstâncias, a "fuga" dos profissionais tem explicado a sua maior mobilidade internacional

3 Para efeitos de economia de texto, não iremos problematizar distinções analíticas em torno da profissão, da ocupação e dos grupos profissionais. Assumimos como ponto de partida que os profissionais que detêm um certificado formal de nível superior e que se encontram associados a atividades relacionadas com o conhecimento.

4 A aproximação entre o funcionamento dos serviços públicos de saúde e o direito privado materializou-se na Lei n, 27/2002, de 8 de novembro, que criou o estatuto jurídico de "hospital EPE" (Entidade Pública Empresarial) e definiu o funcionamento do setor público com base nas regras concorrenciais de mercado.

5 Macedo $(2006$, 2002) destaca a supramacia das análises que valorizam uma vertente de aplicação voltada para a gestão hospitalar. Importa realçar, a este propósito, que já existiam indícios da referida tendência na legislação que regulamenta os hospitais ( $\$ 6$ do Decreto-lei n. ${ }^{\circ} 48357$, de 27 de abril de 1968). 
(Amaral e Marques, 2014), provocando dificuldades na gestão dos recursos humanos afetos ao SNS (em hospitais, e sobretudo, em centros de saúde) ${ }^{6}$. Por sua vez, são apontadas tendências de recomposição de determinados grupos profissionais à luz da incorporação do que se designa "tecnologias da reforma" (Santiago e Carvalho, 2012), que se reportam à submissão destes profissionais aos princípios de gestão e produtividade, tal como aconteceu noutros países, em especial, no Reino Unido. A este nível, o setor da saúde, porque constituído maioritariamente por uma força de trabalho altamente formalizada e detentora de conhecimento, constitui uma "arena" interessante para explorar as consequências ao nível das (novas) formas de regulação estatal e suas práticas de governação na mobilização do discurso do profissionalismo na atualidade.

\section{A agenda empresarial para a saúde em Portugal e as novas prerrogativas profissionais}

Nesta secção, pretende-se compreender melhor o ideário empresarial incorporado na saúde portuguesa, por meio da análise dos principais relatórios de enquadramento das políticas públicas. Estes são: O Futuro da Saúde em Portugal (APAH/ APDH, 2007) e Um Futuro para a Saúde: Todos temos um papel a desempenhar (Crisp, 2014). De forma complementar, cruzaremos esta informação com a análise de conteúdo das entrevistas em profundidade realizadas a informantes privilegiados, nomeadamente, à presidente da Associação Portuguesa para o Desenvolvimento Hospitalar e Professora da Escola Nacional de Saúde Pública da Universidade de Lisboa, o diretor do Programa Inovar em Saúde, da Fundação Calouste Gulbenkian, e a vogal da Comissão Diretiva do mestrado em Gestão de Unidades de Saúde da Escola de Economia e Gestão da Universidade do Minho. A análise privilegiará o confronto entre os pilares do projeto de "mundialização da saúde" e as posições e perceções assumidas por um conjunto de intelectuais orgânicos individuais e coletivos (instituições).

\subsection{Do ideário empresarial na saúde portuguesa}

O livro O Futuro da Saúde em Portugal (APAH/ APDH, 2007) é um compêndio de 24 depoimentos produzidos por intelectuais reconhecidos no campo da saúde portuguesa, entre os quais se incluem dois ex-ministros da saúde e dois ex-diretores nacionais de saúde. Mais de metade ocupou funções de Estado no âmbito da saúde, da educação ou da ciência e tecnologia, um terço desempenhou funções públicas junto da Organização Mundial de Saúde, três exerceram

6 A este propósito, José Manuel Silva, Bastonário da Ordem dos Médicos, declarou em entrevista ao Expresso (24.02.2016) que, em Portugal, não há falta de médicos, mas "um problema de contratação para o Serviço Nacional de Saúde, ou de não contratação ou de dificuldade na contratação”. 
cargos no grupo farmacêutico multinacional Merck Sharp \& Dohme e um era representante das Misericórdias.

A intenção da coletânea foi a de juntar depoimentos de várias figuras públicas sobre o futuro da saúde em Portugal, tendo em vista a "responsabilização de todos e de cada um nas escolhas que forem feitas e na definição do futuro" (APAH/ APDH, 2007: 10). Em princípio, pode imaginar-se um mosaico que se vai formando ao longo da leitura de cada um dos textos, sua abordagem, metodologia e narrativas próprias, revelando, pouco a pouco, o desenho do futuro da saúde em Portugal. Contudo, pretende-se, aqui, observá-lo como uma peça política, articuladora de um projeto coeso para orientar a reforma do sistema de saúde no país.

A totalidade dos textos afirma que, apesar do sucesso do SNS e das melhorias significativas nos índices de saúde da população portuguesa ao longo de sua existência, é necessário ajustá-lo aos novos tempos. O novo momento é caracterizado por alterações demográficas, envelhecimento da população, aumento exponencial dos problemas de saúde mental, aumento das doenças relacionadas com os estilos de vida e em que os doentes passam a atuar como consumidores (idem: 135). A principal estratégia do sistema de saúde do futuro deverá ser, nesse sentido, a prevenção de patologias crónicas, com o duplo objetivo de aumentar a qualidade de vida e reduzir gastos em saúde, de acordo com o encontro anual de Davos de 2005, Governors of the World Economic Forum for Health Care, e o relatório da OCDE de junho de 2006, a partir dos quais se afirma que os "gastos com a Saúde continuam a aumentar e, se as tendências perdurarem, os governos terão de aumentar os impostos, cortar as despesas em outras áreas ou aumentar as contribuições dos cidadãos” (idem: 123).

Reitera-se que se trata de uma mudança de paradigma, ou uma nova ordem pós-tradicional, cuja transição "se desloca de modelos assentes na prestação de cuidados em situações agudas para outros voltados para uma visão mais global do sistema" (idem: 221). Pode ler-se, ainda que uma única vez, que o neoliberalismo corresponde a uma regressão civilizacional. Não obstante, o discurso tende para definições mais restritas ao âmbito da saúde. Uma globalização intensificadora, primeiro pilar do neoliberalismo de Terceira Via, é identificada em afirmações como a de que "a globalização não é uma moda nem, muito menos, um álibi para contermos as fronteiras da nossa intervenção”, cujas expressões aparecem representadas por meio do "acesso quase ilimitado à informação", bem como do "livre-trânsito de profissionais no espaço europeu” e das "exigências sanitárias de uma crescente população de imigrantes" (idem: 101).

É possível ler-se em vários trechos a definição de SNS como uma articulação entre o mesmo e as restantes entidades privadas e sociais que com ele se articulam (idem: 176). Adverte-se, a este propósito, que, por um lado, se "a estruturação dos sistemas de Saúde e os cuidados ou as prestações que 
propiciam são reconhecidos como bens de interesse público”, por outro, “a discussão sobre os objetivos e a natureza e dimensão da intervenção do Estado no sector, quer no domínio da prestação, quer no domínio do financiamento” é menos consensual (idem: 221). Neste sentido, o SNS é caracterizado como a "joia da coroa da nossa democracia”, enquanto o princípio da gratuidade geral é considerado "funesto", já que “apenas favorece os mais ricos". Nesta linha de pensamento, defende-se a "modificação da forma de orçamentação, com a criação (...) de um imposto consignado à Saúde de acordo com a capacidade económica de cada um. (idem: 189-192).

A construção do segundo pilar do neoliberalismo de Terceira Via, um novo Estado democrático, expressa-se no pressuposto de que os recursos são escassos e que "o País gasta demasiado em Saúde”, ainda que esteja "abaixo da média europeia”. Assim, a solução passaria pela abertura do Estado às parcerias nacionais e internacionais na área, procurando "dar as melhores soluções a um custo otimizado, quer para o doente, quer para os parceiros". Ainda, nas "parcerias em Saúde, o Estado deve assumir-se como frágil, como pedinte, como devedor" (idem: 91-92).

Todos parecem concordar que o cenário estaria marcado pelo fim das polarizações entre Estado e mercado e pela aceitação de que é necessário ampliar o investimento público no mercado da saúde, dado que este gera empregos e movimenta a economia do país. O papel desse novo Estado seria o de promover os novos mercados da saúde, o empreendedorismo público e a indústria de bem-estar; ou, noutros termos, fortalecer a cadeia de valor na saúde para produzir melhores resultados (idem: 39-44). O documento governamental Pacto de Cooperação para a Solidariedade Social: 1997-2000, é apresentado por mais de um autor como um documento-chave ao articular a iniciativa pública e privada e ao contribuir para "[e]voluir no estatuto dos serviços de Saúde, de forma a permitir uma gestão mais flexível dos recursos humanos, materiais, tecnológicos e financeiros" (idem: 56).

A mudança organizacional proposta para as instituições estatais de saúde passa, por conseguinte, pela redefinição dos papéis de financiador, pagador e prestador - do Estado, dos utentes e do setor privado. Procurando qualificar esta discussão, afirma-se a necessidade de definição da fronteira entre os setores público e privado, promovendo a individualização e a profissionalização de cada um deles, cabendo ao Estado o incentivo ao setor privado para que recupere as infraestruturas de saúde e a concessão às entidades privadas da gestão de unidades hospitalares e outras (idem: 146-149). Pressupõe-se um Estado neutro, capaz de "dar um fio condutor à gestão equilibrada de todas as forças e tensões que a importância de um sistema de Saúde permite desenvolver”, auxiliado, por sua vez, por um sistema de informação e gestão intermédia no combate ao desperdício (idem: 173). 
A exaltação de uma sociedade civil ativa, terceiro pilar do neoliberalismo de Terceira Via, apresenta-se fortemente no conceito de "governação da saúde", definido como uma administração pública de qualidade, animada por empreendedores públicos qualificados, capaz de promover a excelência nas contribuições do setor privado na saúde (idem: 47). Afirma-se que o futuro pressupõe "promover esta postura dialogante com o Governo, o Parlamento, os partidos políticos, as associações de doentes, as organizações dos outros profissionais de Saúde", bem como "com todas as instituições com responsabilidade no domínio do medicamento e da política de Saúde" (idem: 85). A nova dinâmica social implica reforçar a esfera pública não estatal ou a interface público-privada na área da saúde, em que o risco é assumido pelo Estado e a lucratividade é garantida às empresas, reforçando o caráter da mundialização da saúde.

A dinamização de investimentos rentáveis na saúde é a tónica da discussão, a par com a noção de que a produtividade do país deverá sustentar-se numa força de trabalho ativa e, certamente, saudável. O chamado “setor saúde" é considerado sinónimo de riqueza ao criar empregos e gerar oportunidades também no domínio dos consumos de equipamentos e material clínico, pelo que deve passar de importador a exportador, e, finalmente, atuar em projetos turísticos junto de "pessoas com elevados recursos económicos e cuja idade pressupõe necessidades em saúde cuja satisfação deve ser assegurada" (idem: 175). Reforçando a ótica da mundialização da saúde, os centros de excelência ganham centralidade na agregação de valor às empresas.

A implementação da reforma da saúde na ótica apresentada depende, em grande medida, das estratégias de convencimento implementadas e do grau de coesão social alcançado em torno do projeto empresarial para a saúde. De facto, graças ao individualismo como valor moral radical, quarto pilar do neoliberalismo de Terceira Via, a perspetiva da proteção social é transmutada em atuação estatal sobre os "estilos de vida". A promoção de estilos de vida saudáveis e a atuação sobre doenças associáveis a causas do tipo socio-comportamental tornam-se, nesse sentido, elementos de adesão ao projeto em curso, por meio da mobilização da "sociedade portuguesa para a participação em ações de desenvolvimento da qualidade de vida e de assistência na doença a todos os cidadãos", com o "desenvolvimento do voluntariado, como expressão da mais demonstrativa qualidade da condição humana face ao sofrimento" (idem: 185).

Este projeto tem vindo a apresentar reconfigurações significativas na organização do trabalho e relações laborais na área da saúde. A reforma na administração pública assume como características: “adesão voluntária de profissionais e utilizadores, trabalho em equipa multiprofissional, obrigatoriedade de sistema de informação, regime remuneratório sensível ao desempenho, regime de incentivos, contratualização e avaliação" (idem: 139). Tal proposta abarca uma redução do número de profissionais da saúde, em especial de médicos, como funcionários do Estado (idem: 150). Nos termos de um dos autores, 
"há que pôr os médicos (únicos que conhecem os problemas em concreto e os concretos doentes que sofrem) perante as suas responsabilidades económicas” (idem: 205).

\subsection{Atualizações do ideário empresarial quanto ao futuro da saúde em Portugal}

O relatório do Programa Inovar em Saúde, da Fundação Calouste Gulbenkian, intitulado Um Futuro para a Saúde: Todos temos um papel a desempenhar (Crisp, 2014), elaborado sete anos após O Futuro da Saúde em Portugal, apresenta propostas ainda mais concretas na direção apontada no documento anterior. Entre os membros da Comissão Gulbenkian, dos grupos de trabalho e do conselho consultivo, seis são comuns em relação à publicação de 2007.

O documento de 2014 apresenta como tema central a noção de que o futuro da saúde depende do desempenho de todos na construção do novo pacto na área - "os cidadãos, os profissionais da saúde, os professores, os empresários, as autarquias, os governos" (Crisp, 2014: 3). O apelo à noção de um novo pacto na saúde remete para a crise económica e para as consequências que teve junto dos trabalhadores portugueses, com destaque para os profissionais de saúde: "A maioria da população tem sofrido uma redução no seu nível de vida e os funcionários públicos, incluindo os profissionais de saúde do SNS, tiveram uma redução no seu vencimento e viram baixar o valor das reformas que terão no futuro" (idem: 4). Tomando como ponto de partida a definição de que o corte de gastos em saúde é incontornável, apresenta uma proposta de reorientação do modelo de cuidados de saúde no país de modo a reduzir a incidência e a duração das doenças crónicas e, concomitantemente, os custos do sistema. Cabe a "todos" zelar pela meta de redução de $25 \%$ dos custos dos organismos públicos associados à saúde.

Traduzida em recomendações, a proposta traz elementos que podem ser associados à ideia de um novo Estado democrático. A palavra "Estado", contudo, não aparece no documento. As palavras "governo", "governamental" e mesmo "público" aparecem como correlatos do termo ausente, indicando uma reorientação das funções do Estado, que se torna parceiro de "todos” no gestão do novo modelo de cuidados e promoção da saúde, que se apresenta como centrado já não no hospital e na doença, mas nos cuidados domiciliários e na saúde. Nesta parceria, cabem à esfera pública a manutenção de um fundo com recursos para essa transição; o fomento da melhoria contínua da qualidade desses cuidados por meio da acreditação, do registo e da divulgação de boas práticas; e a colaboração com a investigação e a indústria através da criação de centros nacionais para o desenvolvimento de novas práticas, tecnologias e serviços.

Afirma-se que Portugal deve tirar vantagem dos progressos da ciência e tecnologia através da colaboração eficaz entre o SNS, a comunidade científica 
e a indústria da saúde. Na mesma linha, propõe-se o acordo público-privado como enquadramento para contratação de serviços privados pelo SNS, salvaguardando o interesse público e trazendo novos recursos e potenciais inovações ao sistema de saúde. A mudança da infraestrutura em saúde, desenvolvendo processos de contratualização e contratação, abrindo os serviços de saúde a novos métodos e formas de prestação seria uma das três estratégias centrais para a sustentabilidade do sistema (as outras duas são a prevenção e a redução do tempo de enfermidade e a aplicação eficaz da evidência científica). Tais afirmações exprimem uma visão do que seja o "País" em relação à distribuição das vantagens para toda a sociedade. Supõe, nesse sentido, uma neutralidade do Estado e uma imparcialidade das opções políticas que engendra, que lhe garantiria capacidade de salvaguarda do interesse público a despeito da participação dos interesses privados na produção dos serviços e ações de saúde.

A noção de sociedade civil ativa também dá suporte à proposta, segundo a qual um Conselho Nacional de Saúde deve ser constituído como uma instância "politicamente independente". Com a participação dos cidadãos e de todos os setores da sociedade, teria a missão de tutelar o pacto para a saúde e funcionar como consultor para as políticas que se associam a essa visão. "Todos" deviam estar representados nos órgãos de gestão das instituições em saúde e as autarquias deveriam incluir a saúde e as organizações de saúde nas suas parcerias locais de assistência social e de apoio ao trabalho e ao planeamento intersetoriais. Mais, “todos” (autarquias, organizações de saúde, organizações do mercado, Ministérios adequados) deveriam encontrar maneira de envolver as organizações de voluntários e as redes informais de cuidadores no novo sistema de saúde e prestação de cuidados.

$\mathrm{Na}$ verdade, o novo pacto da saúde projeta uma nova relação entre Estado e sociedade civil para a produção de um modelo de promoção e prestação de cuidados de saúde em que o Estado se desincumbe da prestação direta e se torna mais permeável aos interesses da indústria, na perspetiva da mundialização da saúde, enquanto os organismos da sociedade civil assumem os cuidados de uma população cada vez mais envelhecida e sujeita a doenças crónicas. No plano individual, a proposta reforça o individualismo como valor moral radical, na medida em que põe, por um lado, nas mãos dos sujeitos individuais e suas famílias a informação e, por outro, a responsabilidade da escolha de estilos de vida mais ou menos saudáveis, repartindo os custos dos cuidados de longa duração com as famílias e comunidades.

A proposta inclui a reorientação das relações de trabalho na área da saúde, considerando-se que "os recursos humanos [são] o maior valor dos cuidados de saúde, mas, em contrapartida, são responsáveis por $60 \%$ das despesas do SNS” (Crisp, 2014: 14). Afirma-se que “práticas há muito realizadas terão de mudar" a partir da "redefinição de funções, com maior flexibilidade das mesmas e ênfase na informação partilhada e no trabalho em equipa” face às novas 
possibilidades criadas tanto pelas parcerias com doentes, como a partir de tecnologias inovadoras (idem, ibidem).

\subsection{Perspetivas sobre o atual processo de empresarialização da Saúde em Portugal}

As entrevistas em profundidade realizadas para esta investigação contribuem para a compreensão das atualizações no pensamento empresarial na área da saúde em Portugal após a publicação das duas obras apresentadas anteriormente. Apesar da riqueza de informações captadas nas entrevistas, e tendo presente o propósito deste artigo, optou-se por destacar as que permitem reforçar os posicionamentos assumidos acerca da empresarialização na área da saúde em Portugal. A esse respeito, atente-se à seguinte passagem:

A forma como se articulam e como são as regras de mercado em Portugal não estão, exatamente, num verdadeiro equilíbrio de mercado, como noutros locais. (...) para já, é difícil aceitar e assumir que a saúde é um verdadeiro mercado, porque nós não temos um produto a funcionar aqui, como no mercado normal. No mercado normal, a oferta induz a procura. Na saúde, em princípio, isso também pode acontecer, mas é o menos desejável, porque o mais desejável era que a oferta fosse condicionada pelas necessidades em saúde e não que condicionasse a procura, como num mercado normal. Isso desvirtua o princípio de mercado, logo à partida. (...) Depois, temos também alguma dificuldade de ajustamento das regras puras de mercado, sobretudo em países como o nosso, em que a criação do Serviço Nacional de Saúde tem quarenta anos (Presidente APDH/ Professora da Escola Nacional de Saúde Pública).

Já o diretor do Programa Inovar em Saúde explicita uma outra abordagem sobre o panorama atual na governação em saúde. Refere que há "uma corrente, em Portugal, que defende que nós deveríamos ter uma coisa que é a produção dos atos de saúde e outra, que é a contratualização dos atos de saúde". Para ele, o Estado não deveria ser, ao mesmo tempo, prestador e pagador: "Deve ficar para o papel de pagador e regulador e deixar a prestação livre - é um conceito liberal do mercado". Ainda na mesma linha, importa diferenciar o SNS e o Sistema Nacional de Saúde, definindo este último pela incorporação de prestadores públicos e privados. O papel dos prestadores privados asseguraria a diversificação da oferta, garantindo melhores e mais confortáveis instalações dos hospitais públicos. Uma diferença apontada é que as estruturas privadas "podem fazer tudo desde o princípio, enquanto nos hospitais [públicos] já existe uma estrutura feita e posso ter funcionários que não são bons, mas tenho que convencê-los a ser melhores, ou ficar com eles como estão". Afirma, ainda, que, nos hospitais privados, "entre a necessidade e a decisão, não há patamares", enquanto, nos hospitais públicos, "os administrados hospitalares inundaram os hospitais” (Diretor do Programa Inovar em Saúde). 
Sobre o papel do setor privado na saúde, a presidente da APDH afirma que "a prestação privada é um caminho que eles estão a tentar impor e eu acho que o mercado deve ser composto de tudo: público, privado e social”. Apresenta uma reflexão sobre as mudanças recentes no quadro epidemiológico e de restrição orçamental estabelecida pelo Estado português e suas implicações para a saúde coletiva, interrogando-se: "Dado que não temos mais dinheiro, tiramos onde? Damos a quem pode comprar adicionalmente, retiramos de outras margens? A que margens é que vamos? Essa é a discussão que fazemos neste momento e não é fácil fazê-la”.

A entrevistada seguinte, vogal da Comissão Diretiva do mestrado em Gestão de Unidades de Saúde da Escola de Economia e Gestão da Universidade do Minho, elabora as suas reflexões a partir do estudo de doutoramento que realizou sobre os modelos de gestão hospitalar em Portugal em 2007, período anterior ao que define como de abertura de portas "para novos modelos, nomeadamente para as parcerias público-privadas”. Segundo a entrevistada:

Em 2007, o modelo que mais avançou foi o modelo EPE, gerido segundo o modelo empresarial. Em termos práticos, o que é que isto significa? (...) Um hospital EPE é uma empresa e, portanto, tem que ser regido segundo as regras comerciais normais de uma empresa. Não é $100 \%$ livre, como uma empresa privada, apenas porque tem capitais públicos, faz parte do Ministério da Saúde e, ao fazer parte, tem que cumprir uma série de requisitos, mas só nesses termos. Se eles quiserem comprar uma máquina qualquer ou um medicamento na farmácia da esquina, alguém que tenha isso nas suas funções vai à farmácia da esquina e compra.

Em relação à contratação dos trabalhadores, no modelo EPE, o concurso público não é obrigatório. A chegada do modelo de gestão empresarial também modificou o perfil dos quadros administrativos, incorporando profissionais formados na área de gestão em detrimento dos médicos, ainda que com especialização em administração. A contratação desses profissionais continua a dar-se por nomeação do Ministério da Saúde. Ainda que, em Portugal, os serviços de saúde sejam maioritariamente prestados por entidades públicas, ou ligadas de alguma maneira ao setor público, são significativas as mudanças em curso:

(...) o que o Estado quer é que seja substituído e que seja comprador de serviços, não fornecedor. Os grupos econômicos aperceberam-se disso e entraram em força na oferta dos cuidados de saúde. Há já bastantes hospitais privados. Aqui, em Braga, neste momento, o mesmo grupo tem dois hospitais privados, só na zona de Braga. Portanto, temos o grupo da Trofa, que tem um hospital privado e que, em maio, abriu no centro da cidade uma outra unidade com toda a oferta que tem 
no outro, a três quilômetros de distância (Vogal da Comissão Diretiva do mestrado em Gestão de Unidades de Saúde).

A tendência apresentada de alteração do papel do Estado de fornecedor para pagador dos serviços de saúde expressa-se fortemente nos termos como se estabeleceram as parcerias público-privadas:

No fundo, o Estado trocou a propriedade dos edifícios, dos equipamentos, por alguém exterior, privado, e, em troca, dá a exploração por quinze a vinte e cinco anos. O privado entra, constrói o hospital, compra os equipamentos, compra tudo que é infraestrutura e, em troca, recebe uma mensalidade do Estado e, ainda, todos os gastos inerentes à atividade que é contratada anualmente através do contrato-programa. E quem gere é o privado. Têm um valor que é concertado todos os anos e, em troca, têm a garantia de fornecer um conjunto de atividades hospitalares a uma zona que foi previamente estabelecida ao nível do Serviço Nacional de Saúde (Vogal da Comissão Diretiva do mestrado em Gestão de Unidades de Saúde).

\section{Notas finais}

Os depoimentos recolhidos no contexto das entrevistas aprofundadas revelam que o que se projetava para o futuro da saúde em Portugal nos documentos analisados vem sendo implementado há, pelo menos, uma década por meio da reconfiguração do papel do Estado. Este tende a "desligar-se" progressivamente da prestação direta e passa a fomentar o avanço da empresarialização da saúde.

A mundialização da saúde tem orientado as políticas de saúde em Portugal para além da contenção de custos e da privatização dos serviços. O Estado tem fomentado a criação de sistemas cuja fronteira entre público e privado vem sendo rompida. O incentivo à corresponsabilidade social estende-se a "todos", desde administradores (sejam eles pessoa física ou jurídica), a trabalhadores e utentes, estes últimos renomeados clientes dos serviços de saúde. A reflexividade social constitui uma premissa para o estímulo do Estado reformado na tentativa de encontrar o conhecimento e a informação que orienta a participação - entendida como colaboração para melhoria dos serviços e do atendimento, em si - e a escolha de estilos de vida saudáveis para prevenção das doenças.

Os problemas de saúde associados ao envelhecimento e à predisposição genética para a doença e a classe social são preocupações centrais quando se discute a sustentabilidade financeira do Estado. Projeta-se que os mesmos poderão ser superáveis através de investimento esclarecido, planeamento de longo prazo e gestão preventiva de risco. Porém, considerando os pilares da mundialização da saúde, fica patente que a governação da mesma tende a reforçar os cidadãos 
com mais recursos financeiros face aos que detêm menores rendimentos económicos. Aqueles são assumidos como "investidores na saúde”, sendo levados a tomar medidas preventivas contra a doença futura, enquanto os desapossados sociais são levados a assumir o papel de autogestão e a realizar melhorias incrementais e de curto prazo nas suas condições de saúde e de vida.

\section{Referências bibliográficas}

AMARAL, Susana, MARQUES, Ana Paula (2014), "Emigração Portuguesa de Profissionais de Saúde: (Di)Visões em torno de um fenómeno emergente", in M. I. Martins, A. P. Marques, N. R. Costa e A. Matos (Orgs.), Trabalbo em Saúde, Desigualdades e Políticas Públicas (E-book), Edição CICS-UMinho/ ENSP/FIOCRUZ, pp. 141-158.

APAH (Associação Portuguesa dos Administradores Hospitalares)/ APDH (Associação Portuguesa para o Desenvolvimento Hospitalar) (2007), O Futuro da Saúde em Portugal, Lisboa, Companhia de Ideias.

BANCO MUNDIAL (1997), O Estado num Mundo em Transformação: Informe obre o desenvolvimento mundial, Washington, D.C., Banco Mundial.

BEZES, Philippe, DUMAZIÈRE, Didier (2011), "Introduction (dossier-débat): New Public Management et Professions dans l'Etat: Au-delà des oppositions, quelles recompositions”, Sociologie du Travail, 53, pp. 294-305.

BOLTANSKI, Luc, CHIAPELLO, Eve (1999), Le Nouvel Esprit du Capitalisme, Paris, Gallimard. BOYER, Richard (coord.) (1986), La Flexibilité du Travail en Europe, Paris, La Découverte.

CASTELLS, Manuel (2003), A Era da Informação: Economia, sociedade e cultura, vols. I, II e III, Lisboa, Fundação Calouste Gulbenkian.

CORREIA, Tiago (2012), Medicina: O agir numa saúde em mudança, Lisboa, Mundos Sociais.

CRISP, Lord Nigel (2014), Um Futuro para a Saúde: Todos temos um papel a desempenhar, Lisboa, Fundação Calouste Gulbenkian.

DUBAR, Claude, TRIPIER, Pierre (1998), Sociologie des Professions, Paris, Armand Colin.

EVETTS, Julia (2012), "Sociological Analysis of the New Professionalism: Knowledge and expertise in organizations”, in T. Carvalho, R. Santiago e T. H. Caria (orgs.), Grupos Profissionais, Profissionalismo e Sociedade do Conhecimento, Porto, Afrontamento, pp.13-27.

EVETTS, Julia (2010), “Reconnecting Professional Occupations with Professional Organizations: Risks and opportunities”, in L. Svensson e J. Evetts (ed.), Sociology of Professions: Continental and anglo-saxon traditions, Goteborg, Bokforlaget Daidalos.

FALLEIROS, Ialê, PRONKO, Marcela Alejandra, OLIVEIRA, Maria Teresa Cavalcanti (2010), "Fundamentos Históricos da Formação/ Atuação dos Intelectuais da Nova Pedagogia da Hegemonia", in L. M. W. Neves (org.), Direita para o Social e Esquerda para o Capital: Intelectuais da nova pedagogia da hegemonia no Brasil, São Paulo, Xamã, pp.39-95.

GIDDENS, Anthony (2001), Terceira Via: Reflexões sobre o impasse político atual e o futuro da social-democracia, Rio de Janeiro, Record.

KULMANN, Ellen (2012), "Professionalism Matters: Unpacking the knowledge-power nexus in healthcare governance”, in T. Carvalho, R. Santiaga e T.H. Caria (orgs.), Grupos Profissionais, Profissionalismo e Sociedade do Conhecimento, Porto, Afrontamento, pp.151-162.

MACEDO, Ana (2006), "A Qualidade na Formação em Contexto Hospitalar: Uma reflexão crítica", in M. Silva e Costa e M. E. Leandro (orgs.), Participação, Saúde e Solidariedade: Riscos e Desafios, Associação Ibero-Americana de Sociologia das Organizações (AISO), Braga, Universidade do Minho, pp.335-346. 
MACEDO, Ana (2002), “O Hospital como Empresa: Representações e opiniões de uma Amostra de Enfermeiros”, Enfermagem, 27/ 28, pp.16-25.

MARQUES, Ana Paula (2014), "Mercados de trabalho no sector da saúde: profissionalismo, paradoxos e dilemas de regulação”, in M. I. Martins, A. P. Marques, N. R. Costa, A. Matos (Orgs.), Trabalho em Saúde, Desigualdades e Políticas Públicas, (Ebook), Edição CICSUMinho/ ENSP/FIOCRUZ, pp.127- 139.

MARQUES, Ana Paula (2009), "Novas Legitimidades de Segmentação do Mercado de Trabalho de Jovens Diplomados”, Revista Portuguesa de Educação, 22 (2), pp.85-115.

NEVES, Lúcia M. W. (org.) (2010), Direita para o Social e Esquerda para o Capital: Intelectuais da nova pedagogia da hegemonia no Brasil, São Paulo, Xamã.

SANTIAGO, Rui, CARVAlHO, Teresa (2012), Grupos Profissionais, Profissionalismo $e$ Sociedade do Conbecimento, Porto, Afrontamento.

SENNETT, Richard (2007), A Cultura do Novo Capitalismo, Viseu, Relógio D’Água.

SILVA, Mariana Vieira (2012), "Políticas Públicas de Saúde: Tendências recentes", Sociologia, Problemas e Práticas, 69, pp. 21-128.

SVENSSON, Lars, EVETTS, Julia (2010), Sociology of Professions: Continental and anglo-saxon traditions, Goteborg, Bokforlaget Daidalos.

Agradecimento especial aos entrevistados pelo tempo disponibilizado no quadro da realização desta pesquisa, nomeadamente, à Presidente da APDH e Professora da Escola Nacional de Saúde Pública, ao Diretor do Programa Inovar em Saúde e à vogal da Comissão Diretiva do mestrado em Gestão de Unidades de Saúde. 